\title{
Getting Boys to Read
}

\section{Philip MacMillan}

\begin{abstract}
"As the technology we use becomes more complex, formal qualifications become ever more important and as a result literacy demands are being driven ever higher in all occupations. There is a need then for educators to turn out readers who will be able and willing, to read for a variety of reasons and who will be able to deal effectively with materials that are neither inherently interesting to them nor easy to understand.
\end{abstract}

\section{The gender issue}

There is abundant evidence in the literature to show that boys on the whole are slower to acquire literacy than girls and that once they acquire it they tend to use it less than girls. However, before we tar all boys with the same brush it should be pointed out that the reported gender discrepancies in reading apply to some boys but not to all. The differences among boys and the differences among girls are greater than the differences between them. Boys develop language skills at a slower pace than girls and reading is a language-based skill. This is reflected in the numbers of boys referred for special help for reading, the ratio of boys to girls can reach 3 or 4 to 1 .

The research has thrown up a list of possible innate differences between boys and girls that could affect their learning development especially in the area of reading.

Functional styles; in kindergarten and the early grades boys tend to be what is described as 'kinetic' in other words they prefer to move about a lot, girls are much more inclined to sit still and this factor is at a premium in a classroom setting and would contribute towards girls getting ahead faster than boys.
Organizational abilities; boys tend to act in a less organized and impulsive manner than girls, boys have better hand eye coordination but poorer fine motor skills.

Language development; it is well known that girls develop language at a quicker rate than boys. Girls are better able to comprehend narrative and expository texts, boys on the other hand are better at information retrieval.

Self-perception; girl's perceptions of their abilities as readers, is usually higher than boy's perceptions at the same level of attainment.

Attitudes to reading; girls value reading more than boys, girls are more inclined to use reading as a leisure activity.

\section{Classifying reluctant readers}

We can broadly categorize reluctant boy readers into those who can read well and those who cannot. In the case of competent readers there is a proportion who do read well and make good progress, these we do not need to worry about. There is another proportion who, whilst similarly competent tend to read little. These are the students who can increasingly frustrate the teacher. There are also those who have real difficulties in dealing with print. These distinctions are important, as it will inform the choice of methods needed to improve motivation for reading.

\section{Competent but reluctant - some reasons why}

The research shows that there is a population of boys whose reading skills are good but who are reluctant to use them in any sustained way. These boys start off well but by the end of grade 5
/ 6 and onwards they start to falter and become reluctant readers. There are many explanations offered for this. It was once thought that the difference between boys and girls in terms of their learning was a result of socialization pressures. This is now thought to be in error and the new conception is that boys and girls brains are different and the differences between them may have more to do with genetics and rates of maturation than child rearing methods, especially in the early stages of reading development. In the later stages social factors such as peer pressures and attitudes to learning will enter the equation and these can be difficult to figure out as they also interact with socio-economic and ethnicity factors.

\section{Reluctant for good reasons}

There are boys whose reluctance to read is caused primarily by their level of reading development being such as to make dealing with print in any sustained way difficult for them.

Reading is a complex skill and there are many reasons why an individual may experience reading delay, however the empirical research literature is firm on the point that reading delay in most students is caused by difficulties in dealing with the complexities of speech especially in relation to phonological awareness and phonological processing. There are two main components to this, one involves the segmental analysis of speech for everyday listening and speaking, this is acquired through exposure, the other is meta-phonological analysis aimed at analysing the sound structure of speech into the phonemic components associated with the alphabetic structure and orthographic rules of the writing system, this needs to be learned.

\section{Our writing system}

Our writing system is organ- 
ized at the phonemic and morpho-phonemic levels, that is a level of organization somewhere between the meaning structure (morphology) and the sound structure (phonology / phonics). That being said, it must be remembered that phonics is only a heuristic way to help the learner acquire the real rules that govern our orthography which although relatively complex is for the most part rule bound. The research indicates that the first step is to ensure mastery of the phonemic aspects of the code that is the one to one, one to many and many to one letter sound correspondences. However, this needs to be taught not as isolated drills but in the context of words and sentences.

\section{Possible sources of reading delay}

Glue Ear or Otitis Media has been implicated in reading delays; it affects the ability to listen in the presence of noise. There is also the fact that glue ear may have affected the sound patterns laid down within the student's brain and this can affect ability to categorize speech sounds (phonemes). Our writing system is based on phonemes so reading delay is to be expected. Pay special attention to those students who come to you with a history of glue ear and give them plenty of work to build their phonological awareness.

\section{Functional style}

Boys appear to have a preferred style of working in the learning environment. They seem to respond best when the work is in relatively 'bite size bits ' and has a specified time limit. They prefer brisk paced lessons with an obvious structure. Lessons and activities that challenge learning proficiencies through short-term goals are more likely to motivate reluctant learners. Most important is that when they receive regular positive feedback proficiency increases.

\section{What we do at Beacon?}

At Beacon our lessons are brief but intense, error free, in a one to one tutorial format of around 2030 minutes in length with a similar practice period immediately after. The materials are highly structured and multi sensory with immediate feedback. The activities include analytic and synthetic phonics, word and sentence reading and comprehension exercises. The student's own or self-voice is used as the teaching medium. Use of the self-voice has been shown to exert positive effects on phoneme discrimination and shortterm memory. The student is very much in control of the learning. The lesson is error free and use of their own voice provides a model of competent behaviour in reading with which they can readily identify - themselves. This method of edited performance modelling is used extensively in the fields of sport and performance generally and derives from Bandura's work in social learning theory. Visualizing competent performance is also useful in building motivation.

\section{A few points to ponder}

Research has put forward the idea that boys might not read as much as girls in a classroom setting because much of the reading material may be of little interest to them.

Boys prefer books that appeal to their sense of humour; they prefer action oriented fiction and science fiction or fantasy material such as the Harry Potter books.

Outside of the boys tend to read comics, magazines, instruction manuals etc. These materials are rarely found in a classroom and their inclusion might kickstart boys into reading more in the school setting. Make sure that within the school there is a wide range of reading materials that are known to appeal to boys.

Most elementary teachers are female; at home it is usually the mother who reads to the children so boys seldom have male models for reading with whom they could identify. So recruit your local sports or media personalities to come in talk to just the boys about the benefits of reading.

Lessons should be brief with a goal that is fairly close in time.

Materials need to focus the student's attention on paying attention to the feedback from his / her own speech.

Repeated reading is useful in building fluency.

Give immediate feedback on responses if at all possible.

If you can do all this in a one to one setting you will take away the embarrassment that failure can bring and make it into something to be laughed about. Good for teacher - student relationships and self esteem building.

To quote the Hall Dennis Report Living and Learning:

"If a child is learning then he or she cannot be failing"

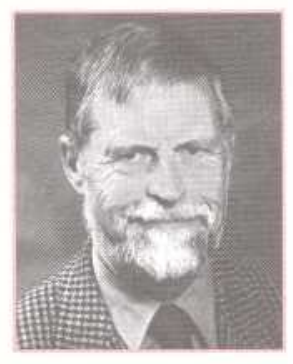

Philip MacMillan left school at age 15 and after many jobs ended up at age 28 driving double decker buses. At age 31 he decided to go to University and study psychology and education. He spent a few years as a classroom teacher and later became a school psychologist. Moving to Canada from Britain, Philip started developing the Beacon method whilst working as a school psychologist in Goose Bay Labrador. Philip is now the Program Director of Beacon Literacy Inc. based in Calgary, Alberta.

www.literacycanada.com 